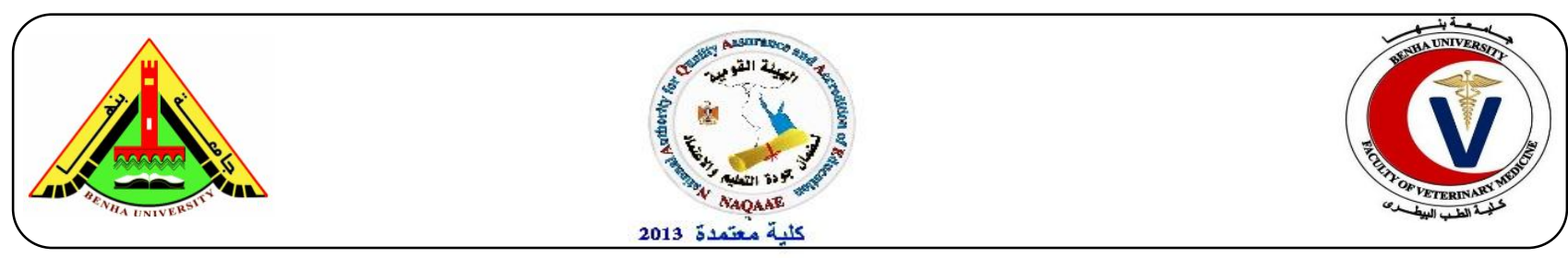

\title{
SURVEY ON SOME HORMONAL RESIDUES IN CHICKEN MEAT, LIVER AND KIDNEYS
}

\author{
Hemmat, M. Ibrahim ${ }^{\text {a }}$, Reham, A. Amin a ${ }^{\text {, Omaima, M. Diab }}{ }^{\text {b }}$ and Asmaa, E. Hassan ${ }^{\text {b }}$ \\ ${ }^{a}$ Food Hygiene Department, Faculty of veterinary Medicine, Banha university. \\ ${ }^{b}$ Food Hygiene Department, Animal Health Research Institute, Dokki, Giza.
}

\begin{abstract}
A B S T R A C T
The study was planned to estimate the $17 \beta$-Estradiol and Zeranol residues in 100 samples of chicken carcasses and their livers and kidneys. Samples were randomly collected from different localities in Cairo and Giza markets and were analyzed using Enzyme-linked Immuno Sorbent Assay (ELISA) method. The mean values (ppb) of 17 $\beta$-Estradiol in chicken muscle, livers and kidneys were $0.782 \pm 0.07,1.53 \pm 0.09$ and $2.077 \pm 0.08$, respectively. While, the mean values (ppb) of Zeranol in chicken muscle, livers and kidneys were $0.1065 \pm 0.01,0.1235 \pm 0.01$ and $0.262 \pm 0.02$, respectively. Accordingly it seems that the use of these hormones in chicken farms constitute a public health hazard, so we need to routinely monitor these chemical residues as food quality control measure.
\end{abstract}

Key words: $17 \beta$-Estradiol, Zeranol, anabolic hormones

\section{(http://www.bvmj.bu.edu.eg) (BVMJ-34(2): 23-30, 2018)}

\section{INTRODUCTION}

Chicken meat is widely available, relatively in expensive and can be of central importance in helping to meet shortfalls in essential nutrients, particularly of impoverished people. The incidence of several common metabolic diseases associated with deficiencies of critical dietary minerals, vitamins and amino acids can be reduced by the contribution of poultry products rich in all essential nutrients except vitamin C. (Fafrrell, 2014).

Anabolic agents are substances with physiological functions similar to those of human sex steroids, which increase nitrogen retention and protein deposition in farm animals (Hoffmann and Evers, 1986).

$17 \beta$-Estradiol affects body weight by enhancing secretion of growth hormone but it result in a great suppression in $\mathrm{LH}$ values. Generally withdrawal of estradiol greatly influenced by the level of lipid content of different tissues.

The consumption of meat containing estrogenic material resulted in fluctuation in estrogenic hormones and significant disorder in gonadotrophins of lactating mother (Ayat 1987).

Zeranol is a synthetic hormone obtained from the mycotoxin zeralenone which is produced from the fungus Fusarium graminearum. It is used as growth promoter for fattening animals and it has estrogenic 
effect (mimics 17- $\beta$ estradiol). Their residue in meat and milk is possible cause of premature sexual development in children.

The most serious potential hazards arising from using of anabolic steroids are the tissue residues of these substance and its metabolites. The effect of these residues is greater on human as it can cause early puberty for girls and boys, liver tumors, carcinoma and increase embryo mortality (Ibrahim,2009).

Therfore, the aim of this work is detection of hormonal residues (17 $\beta$ estradiol and zeranole) in local market chickens to determine the amount of hormones that used illegally in farms and marketed without complete withdrawal.

\section{MATERIALS AND METHODS}

2.1. Collection of samples:

A total of 100 samples of chicken carcasses and their livers and kidneys were collected from different localities at Cairo and Giza markets. the samples were collected in polyethylene bags and rapidly transferred to laboratory for detection of their hormonal residues according to manual kits ELISA RBiopharma AG, Darmstadt ,Germany.

\subsection{Preparation of samples}

\subsubsection{Detection of $17 \beta$ - Estradiol residues:-}

1) Skin and fat were removed from the muscle.

2) Ten grams of the ground muscle were homogenized with $10 \mathrm{~mL}$ of $67 \mathrm{mM}$ PBS buffer by mixer for $5 \mathrm{~min}$.

3) Two grams of homogenized sample were mixed with $5 \mathrm{~mL}$ of tertiary butyl methyl ether (TBME) in a centrifugal screw cap vial and shaken vigorously by shaker for 30-60min.

4) The contents were centrifuged at 3000 rpm for $10 \mathrm{~min}$.
5) The supernatant was kept and the extraction with TBME was repeated.

6) The supernatants were combined and evaporated then the dried extract was dissolved in $1 \mathrm{~mL}$ of $40 \%$ methanol for MT and $80 \%$ methanol for TBA.

7) The methanolic solution was diluted with $2 \mathrm{~mL}$ of $20 \mathrm{mM}$ PBS-buffer and applied to a RIDA C18 column (solid phase extraction column with $\mathrm{C} 18$ end-capped sorbent of an average particle size of $50 \mu \mathrm{m}$ ) (Art. No. R2002); flow rate: 1 drop / sec.

- Column was rinsed by flowing of $3 \mathrm{~mL}$ methanol (100\%).

- Column was equilibrated by injection of 2mL PBS - Buffer (20mn).

- $3 \mathrm{~mL}$ of sample was loaded on column.

- Column was rinsed by injection of $2 \mathrm{~mL}$ methanol (40\%).

- Column was dried by pressing nitrogen through it for $3 \mathrm{~min}$.

- Sample was eluted slowly by injection of $1 \mathrm{~mL}$ methanol (80\%) An aliquot of the eluate was diluted with water, then $20 \mu \mathrm{L}$ per well of resulting solution was used in the test.

\subsubsection{Detection of Zeranol residues:-}

1. Fat was removed from the muscle and the sample was grounded.

2. One gram of ground sample was homogenized with one $\mathrm{ml}$ of 20mM PBSbuffer in a centrifugal screw cap vial, then mixed vigorously (vortex)

3. Ten ml of tertiary butyl methyl ether (TBME) was added to the homogenate and shaked carefully for $30 \mathrm{~min}$.

4. Then Centrifuged for $10 \mathrm{~min} / 4000 \mathrm{rpm}$

5. the supernatant (ether layer) was transferred into another centrifugal screw cap vial and evaporated to dryness at $60^{\circ} \mathrm{c}$ 
6. The dried residue was dissolved in $1 \mathrm{ml}$ chloroform and $3 \mathrm{ml}$ of $1 \mathrm{M} \mathrm{NaOH}$ and mixed vigorously for $30 \mathrm{sec}$ (vortex)

7. Then Centrifuged for $10 \mathrm{~min} / 4000 \mathrm{rpm}$

8. The $\mathrm{NaOH}$ extract (upper aqueous layer) was transferred into another centrifugal screw cap vial that contains $250 \mu$ acetic acid $(96 \%)$

9. Five ml of tertiary butyl methyl ether (TBME)was added and mixed for $30 \mathrm{sec}$ (vortex)

10. Then Centrifuged for $10 \mathrm{~min} / 4000 \mathrm{~g}$

11. The sample was freezed out at $-25^{\mathrm{O}} \mathrm{c}$ for approx. $60 \mathrm{~min}$ (lower phase has to be frozen )

12. The supernatant (ether layer) was transferred into another centrifugal screw cap vial and evaporated to dryness at $60^{\circ}$ c

13. The dried residue was dissolved in $2 \mathrm{ml}$ of sample dilution buffer

14. Twenty $\mu 1$ was used per well in the assay.

2.3. Test procedures

The test procedures were done according to the chart enclosed in the kits of RIDA $^{\mathrm{R}}$ and RIDS screen $\mathrm{R}$ is register trademarks of R-Biopharm AG.

Manufacture: R-Biopharm AG,

Darmstadt, Germany. R-Biopharm AG is ISO certified.

The results were calculated by this equation:

$\%$ absorbance $=($ OD sample $/$ OD standard) x 100 , results were calculated as ppt.

In order to obtain the $17 \beta$-Estradiol and Zeranol concentration in ppt actually contained in the samples . the concentration were read from the calibration standard curve. \{for $17 \beta$ Estradiol (Fig.1) \& for Zeranol (Fig.2)\}.

\section{RESULTS}

Mean values of $17 \beta$-Estradiol in chicken muscle, livers and kidneys were $0.782 \pm 0.07,1.53 \pm 0.09$ and $2.077 \pm 0.08 \mu \mathrm{g} /$ $\mathrm{kg}$, respectively.

Mean values of Zeranol in chicken muscle, livers and kidneys were $0.1065 \pm 0.01, \quad 0.1235 \pm 0.01$ and $0.262 \pm 0.02$ $\mu \mathrm{g} / \mathrm{kg}$, respectively. 
Table (1): Statistical analytical results of $17 \beta$ - estradiol residues (ppb) in the examined chicken samples by ELISA method $(n=100)$

$\mathrm{PL}^{*}$ : permissible limit according to EOS (1992)

\begin{tabular}{|c|c|c|c|c|c|c|c|}
\hline \multirow[t]{2}{*}{ Examined tissues } & \multicolumn{2}{|c|}{$\begin{array}{l}\text { Positive } \\
\text { samples }\end{array}$} & \multirow[t]{2}{*}{ Min. } & \multirow[t]{2}{*}{ Max. } & \multirow[t]{2}{*}{ Mean \pm SE } & \multicolumn{2}{|c|}{$\begin{array}{r}\mathrm{PL}^{*} \\
<2 \mathrm{ppb}\end{array}$} \\
\hline & No. & $\%$ & & & & N0. & $\%$ \\
\hline Muscle & 100 & 100 & 0.043 & 0.621 & $0.782 \pm 0.07$ & 100 & 100 \\
\hline Liver & 100 & 100 & 0.379 & 2.957 & $1.53 \pm 0.09$ & 29 & 29 \\
\hline kidney & 100 & 100 & 0.985 & 3.377 & $2.077 \pm 0.08$ & 18 & 18 \\
\hline
\end{tabular}

$\mathrm{PL}^{*}$ : permissible limit according to EOS (1992)

\section{$17 \beta$ - estradiol}

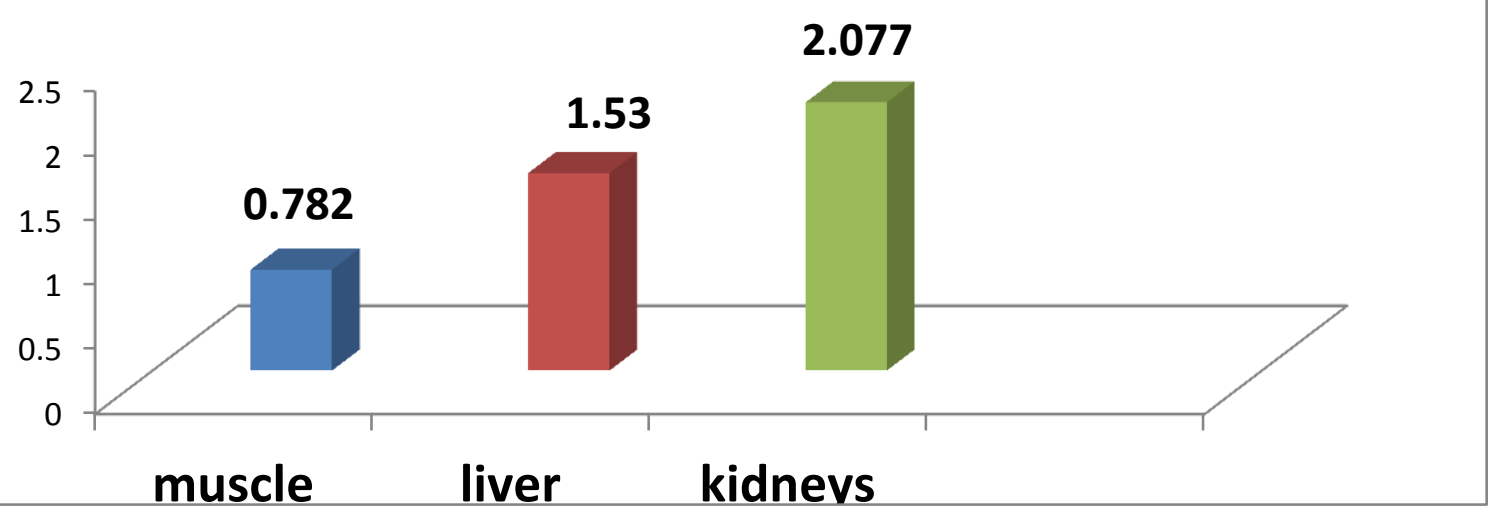

Fig (1): Mean values of $17 \beta$ - estradiol residues in the examined chicken samples by ELISA method 
Table (2): Statistical analytical results of zeranol residues ( $\mathrm{ppb}$ ) in the examined Chicken samples by ELISA method $(n=100)$

MRL*: Maximum residue limit in Muscle (2ppb) in liver (10ppb) according to Codex Alimentarius

\begin{tabular}{|c|c|c|c|c|c|c|c|}
\hline \multirow[b]{2}{*}{ Examined tissues } & \multicolumn{2}{|c|}{$\begin{array}{l}\text { Positive } \\
\text { samples }\end{array}$} & \multirow[t]{2}{*}{ Min. } & \multirow[t]{2}{*}{ Max. } & \multirow[t]{2}{*}{ Mean \pm SE } & \multicolumn{2}{|c|}{ MRL* } \\
\hline & No. & $\%$ & & & & No. & $\%$ \\
\hline Muscle & 100 & 100 & 0.011 & 0.143 & $0.1065 \pm 0.01$ & 100 & 100 \\
\hline Liver & 100 & 100 & 0.106 & 0.192 & $0.1235 \pm 0.01$ & 100 & 100 \\
\hline kidney & 100 & 100 & 0.122 & 0.389 & $0.262 \pm 0.02$ & 100 & 100 \\
\hline
\end{tabular}

commission (2017)

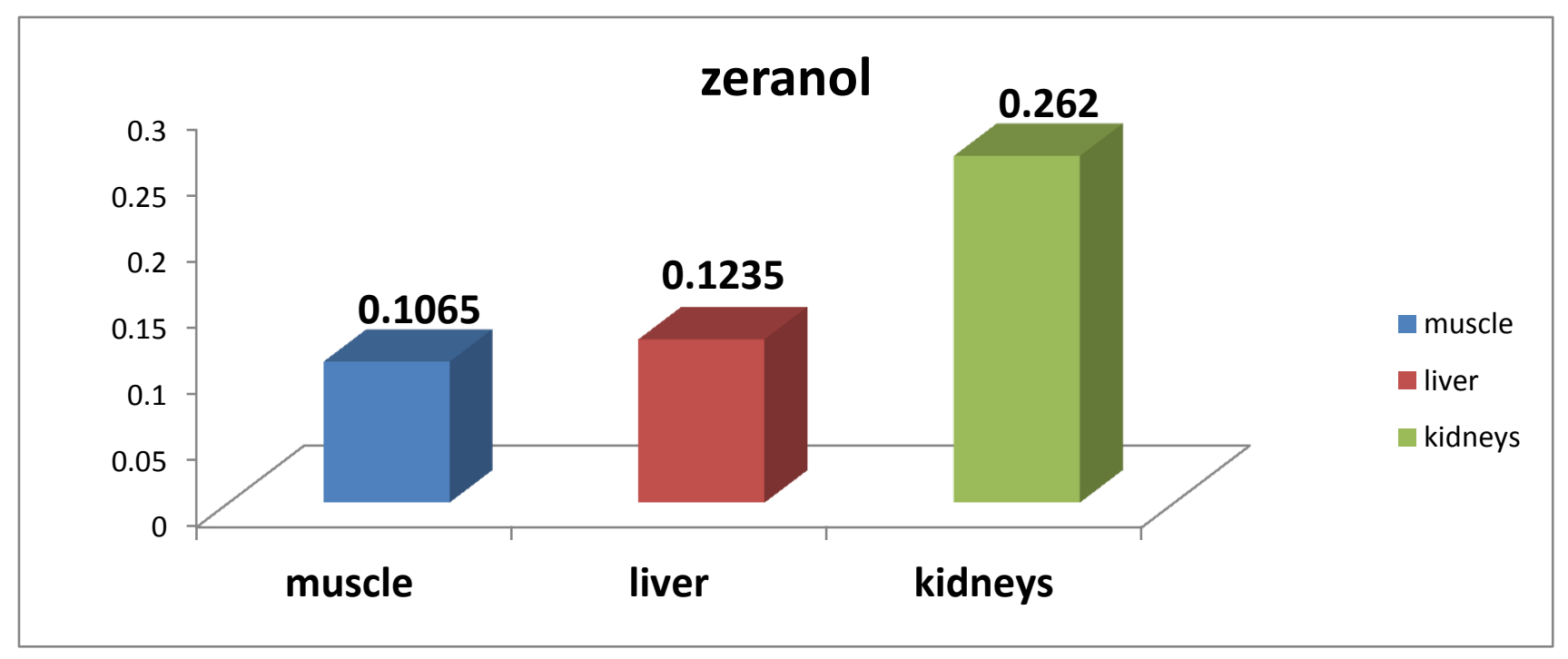

Fig (2): Mean values of Zeranol residues in the examined chicken samples by ELISA method 


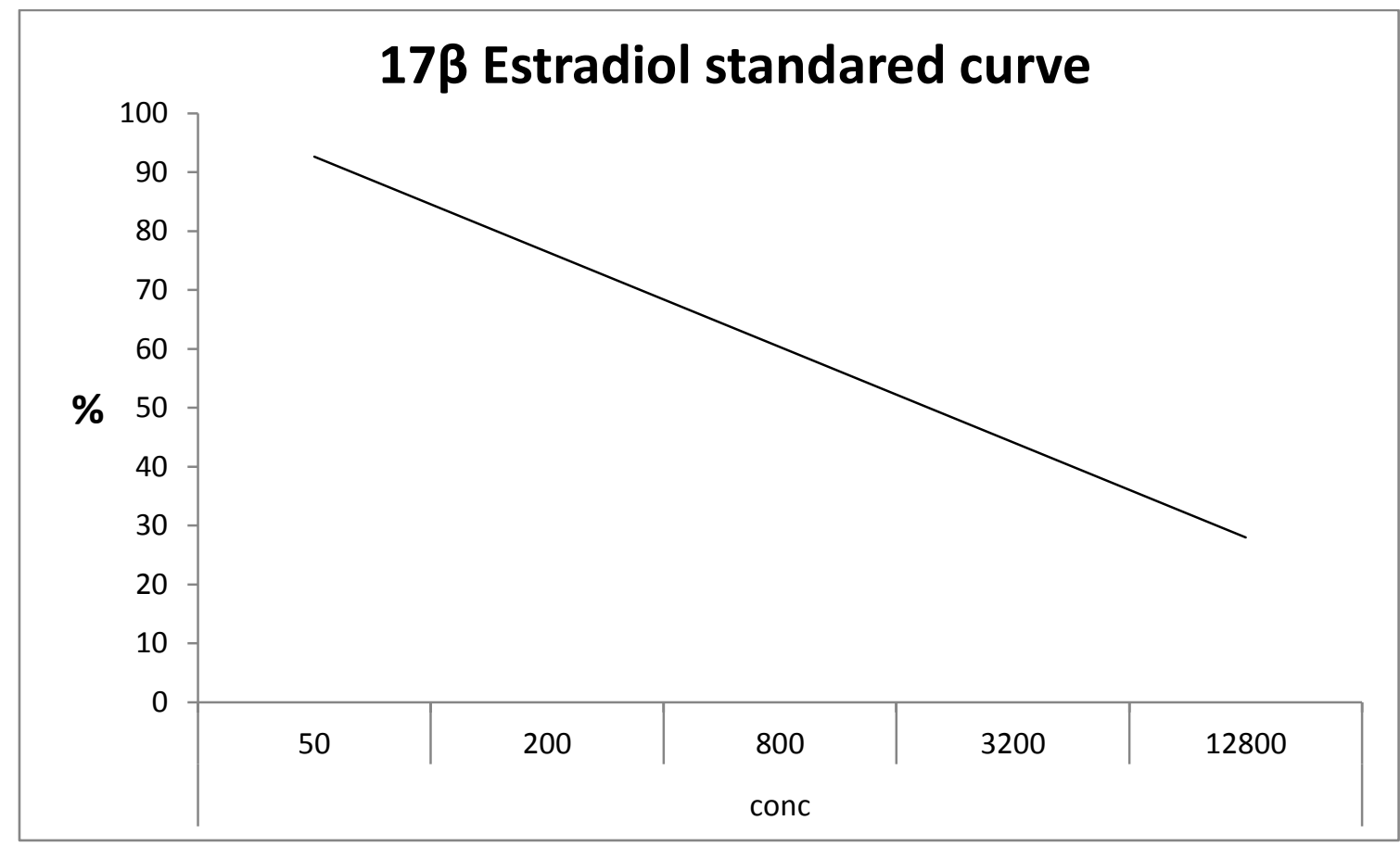

(Fig.A): standard curve of $17 \beta$ Estradiol .

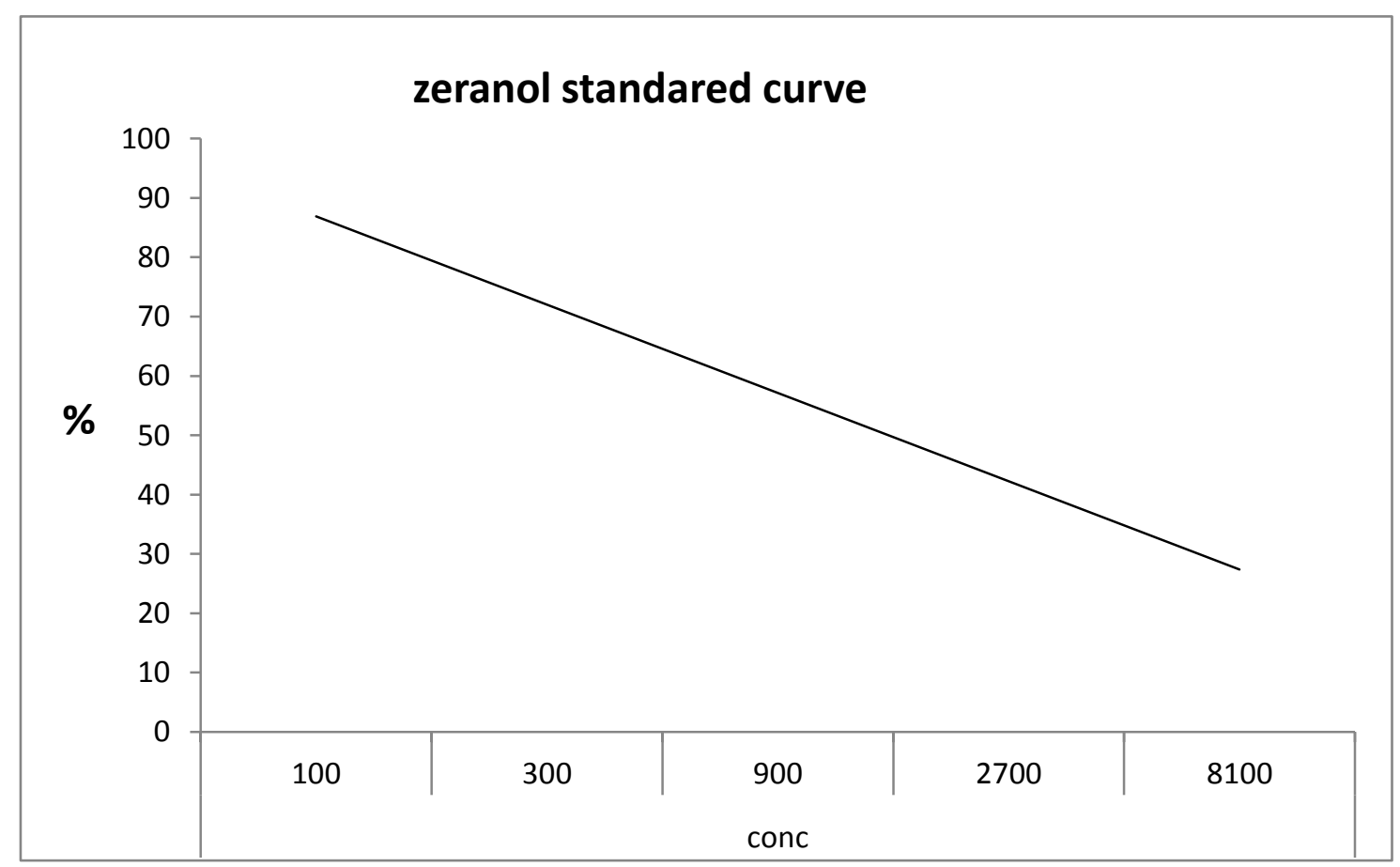

(Fig.B): standard curve of Zeranol. 


\section{DISCUSSION}

Recently, hormones and hormone like substances have been used in livestock production to obtain a high yield performance in shorter period of time. These agents are used to increase weight gain, to improve the food efficiency, storing protein and to decrease fatness. (Asia and Akzira, 2016)

According to the results that obtained by ELISA in table (1) and Fig(1) the mean values of $17 \beta$ - estradiol were $0.782 \pm 0.07$, $1.53 \pm 0.09$ and $2.077 \pm 0.08 \mathrm{ppb}$ with minimum values of $0.043,0.379,0.985 \mathrm{ppb}$ while maximum values of $0.621,2.957,3.377 \mathrm{ppb}$ in muscle, liver and kidneys, respectively

Lower findings were obtained by Doyle (2000) who found 17 $\beta$ - estradiol in chicken meat was ranged from $<0.03-0.02$ $\mathrm{ppb}$. While higher findings were obtained by Sadek et al.,(1998) who found 17ß- estradiol in chicken meat and Liver were 0.865, 4.216 $\mathrm{ppb}$ respectively.

The acceptability of samples according to permissible limit (>2ppb) stipulated by the Egyptian Organization for standardization and quality control (EOS),(1992)is shown in table (1). Accurately, 100 (100\%), 29(29\%) and $18(18 \%)$ samples in muscle, livers and kidneys, respectively. No samples were exceeding the permissible limit stated by Gracey (1986). While EL-Neklawy (1989) and Doyle (2000) found 46,45samples in muscle and fat respectively within the physiological level.

The presence of natural steroid hormones in chicken meat may be attributed to the fact that the natural steroid hormones are secreted by the gonads and adrenals (Rico et al., 1981).
Table (2) and Fig (2) revealed that the mean values of zeranol residues $0.1065 \pm 0.01$ ، $0.1235 \pm 0.01$ and $0.262 \pm 0.02$ ppb with minimum values of $0.011,0.106$ and 0.122 while maximum values of $0.143,0.192$ and $0.389 \mathrm{ppb}$ in muscle, livers and kidneys, respectively.

Lower findings were obtained by Sadek et al.,(1998) who not found any residues of zeranol in chicken muscle. While higher findings were obtained by Xiamong et al .,(2002) who found zeranol residues (2.5 ppb) in liver samples of chickens.

Table (2) indicated that there were no samples above the maximum residue limit (MRL) 2ppb in muscle while, $10 \mathrm{ppb}$ in liver according to Codex Alimentarius Commission (2017)

Accordingly, it seems that the present status of these anabolic hormones in market is not at risk but on the other hand, these results do not exclude the possibility of misuse of these anabolic hormones in the future and significantly increase exposure of humans, particularly children, to trenbolone which may adversely affect health. Therefore, there is need to routinely monitor these chemical residues as a food quality control measure.

\section{REFERENCES}

Asiya, S. and Akzira, O. (2016): The Effect of Hormones on the Quality of Poultry Meat. Faculty of Technology and Biological Resources, Kazakh National Agrarian University, Almaty, Kazakhstan. ISSN: 2349-8080. 3. 1.

Ayat A.M. (1987):Serum hormonal changes during lactation and its relation to mother nursing status and infant growth. Ph.D. Thesis, Fac. Of Med., Cairo university. 
Codex Alimentarius commission (2017) : veterinary drug residues in food

Farrell, D. ( 2014) : The role of poultry in human nutrition. School of Land, Crops and Food Sciences, The University of Queensland, St. Lucia 4072, Queensland, Australia , FAO

Doyle, E. (2000) : Human safety of hormone implants used to promote growth in cattle . Ph. D., Food Research Institute, University of Wisconsin Madison .

El-Neklawy, E.M. (1989) : Determination of hormone residues in different kinds of meat. Ph. D., Thesis , Fac. Vet. Med., Cairo University.

EOS (Egyptian Organization for standardization and quality control) (1992): 2 Latin America street, Garden City, Cairo, Egypt. Cable Tawhid telex: EOS UN 93296.

Gracey J.F.(1998): Chemical residues in meat . Meat hygiene $8^{\text {th }}$ ed. Pp517. Bailliere Tindall, London

Hoffmann, B. And Evers, P. (1986 ): Anabolic agents with sex hormone like activities . Problems of residues. Int. Rice, A.G.(ed.), Drug Residues in Animals, Academic Press, New York.
Ibrahim, H.A.M(2009):Hormonal residues in chicken carcasses .Ph.D. thesis, Beni , suef .Unv. Faculty of vet Medicine.
R-Biopharm AG, Darmstadt, Germany:RIDASCREEN® ${ }^{\circledR} \quad 17 \beta$ - Estradiol ,Enzyme immunoassay for the quantitative analysis of $17 \beta$ - Estradiol, R3601.

Rico, A. G., Burgot-Sacaze , V., Braun, J.P.and Benard , P.(1981): Metabolism of endogenous anabolic agents in cattle - Anabolic agents in beef and veal production, CEC Workship, Brussels.

Sadek I.A., Ismail H.M., Sullman H.N. and Salim M.(1998): Survey of hormonal levels in meat and poultry sold in Alexandria , Egypt. WHO int. publication, 4(2), 239-243

Xiaoming Fang., Jiahua Chen and Dehua Guo (2002) : Detection and Identification of Zeranol in Chicken or Rabbit Liver by Liquid Chromatography-Electrospray Tandem Mass Spectrometry, Drugs, Cosmetics , Forensic sciences journal of AOAC, 85 (4) 